Meta

Journal des tradlucteurs

Translators' Journal

\title{
Terminologie des transports
}

\section{Gérard de Jaham et Jean-Michel Leclercq}

Volume 14, numéro 3, septembre 1969

URI : https://id.erudit.org/iderudit/003435ar

DOI : https://doi.org/10.7202/003435ar

Aller au sommaire du numéro

Éditeur(s)

Les Presses de l'Université de Montréal

ISSN

0026-0452 (imprimé)

1492-1421 (numérique)

Découvrir la revue

Citer cet article

de Jaham, G. \& Leclercq, J.-M. (1969). Terminologie des transports. Meta, 14(3), 160-162. https://doi.org/10.7202/003435ar d'utilisation que vous pouvez consulter en ligne.

https://apropos.erudit.org/fr/usagers/politique-dutilisation/ 


\section{TERMINOLOGIE DES TRANSPORTS}

L'évolution des méthodes de transport a mis en vedette l'usage du container. Il nous a paru intéressant d'examiner quelques mots et expressions qui se rapportent aux techniques nouvelles mises au point pour le transport et la manutention de cet élément ${ }^{1}$.

Container - Terme générique anglais désignant tout ce qui contient, tout récipient. Dans le domaine du transport, s'applique à un cadre métallique qui permet l'arrimage et le transport de colis ou simplement le transport des liquides et des produits en vrac. Il offre l'avantage de pouvoir être manipulé sans que le contenu ait à en souffrir ou doive préalablement être emballé ou protégé. Le terme français correspondant serait cadre. Il y a en effet plusieurs sortes de containers, certains sont à claire-voie, d'autres sont vitrifiés (transport du vin), d'autres sont pliables, ce qui permet de réduire les frais de retour. On les désigne sous le vocable «cadre» qui apparaît d'ailleurs dans la raison sociale de la

1. Bibliographie: Larousse universel; bulletins de l'Union internationale des Chemins de fer (chap. $x$ du R.I.V.); la Vie du rail, nº 1166. 
"Compagnie générale des cadres». Le mot anglais container est passé en français pour désigner un cadre plein, à chargement commode, généralement muni d'anneaux pour le transbordement par grue ou de dispositifs fixes pour le transbordement direct. On trouve par exemple le «container à porteur aménagé », muni de roulettes et qui constitue un ensemble avec le wagon spécialement aménagé qui le porte. Signalons la tendance à adopter conteneur au lieu de container, tendance qui nous semble plus conforme au génie de la langue.

Transcontainer - Terme anglais désignant un conteneur destiné au trafic international et pouvant emprunter successivement différents modes de transport. De nombreux auteurs l'ont adopté en français dans leurs articles. Nous souhaiterions que le Comité d'étude des termes techniques français se prononce sur l'opportunité d'un tel emprunt.

Intermodal - Adjectif qualifiant le transport par conteneurs et qui rend l'idée de l'universalité de ce mode de transport. Nous proposons comme équivalent l'adjectif français universel. D'après le contexte, on parlera de « transport universel » ou de « conteneur universel ».

Roll-on roll-off - Expression illustrant la possibilité de faire passer directement le conteneur du navire au wagon ou du wagon au camion. Cette expression trouve son équivalent en français et se rend par: à roulage direct ou par le néologisme qui nous semble de bon aloi, transroulage, formé comme "transpalette » qui figure au Larousse universel.

Intercontinental, intracontinental - Ces deux adjectifs permettent de distinguer le transport entre continents et le transport à l'intérieur d'un continent. Il n'y a pas de difficulté à rendre le premier par son équivalent français intercontinental. Dans le deuxième cas, on pourra employer transcontinental si le transport s'effectue d'un bout à l'autre du continent ou simplement continental s'il s'agit de relier un point du continent à un autre.

Signalons que la technique du transport par conteneur permet le «porte-àporte intégral », c'est-à-dire la livraison chez le client de marchandises enlevées des usines ou des entrepôts du fabricant. Elle autorise également le transport sans « rupture de charge ».

Pour ne pas quitter le domaine des transports, voici trois expressions qui appartiennent à la terminologie des chemins de fer et de la manutention.

Automated express terminal - Halle automatisée. Ces installations font partie de l'infrastructure «Messageries» des compagnies de chemins de fer. Il s'agit de vastes hangars où les colis les plus divers sont centralisés afin d'y être triés et groupés par destination. Les progrès de l'électronique permettent d'automatiser ces différentes opérations si bien que les expressions: halle de transbordement ou halle mécanisée nous ont semblé périmées.

Temperature controlled equipment - Matériel polytherme. Ce type de matériel comprend toute une gamme de wagons équipés de manière à transporter les denrées périssables dans certaines conditions de température. Ils peuvent donc, soit fournir du froid, soit, au contraire, assurer le réchauffage du chargement. Cette variété de situations nous a incités à employer l'adjectif polytherme par opposition à isotherme. 
Tail gate loader - Hayon élévateur. Les véhicules de livraison sont désormais très souvent munis d'un dispositif placé en bout de caisse et destiné à faciliter le déchargement. Il s'agit ni plus ni moins d'une sorte de monte-charge hydraulique qui, en position haute, forme le hayon et, en position basse, vient se poser sur le sol. Notre solution a trouvé une confirmation dans l'Usine nouvelle ${ }^{2}$.

Gérard de JahaM ET JeAN-Michel LeClerCQ

2. Edition supplémentaire, septembre 1967 ,p. 7. 